\title{
Job Satisfaction in Business Enterprises in Nepal
}

\author{
Dr. Sushil Bhakta Mathema*
}

\begin{abstract}
The term management is strongly tied with leadership as it pervades as the management functions. The role of leadership in management is so immense that it is only leadership that can earn result or profit in organizations. Employee job satisfaction is an attitude that people have about their job and the organizations in which they perform their jobs. Numerous factors influence job satisfaction, including salaries, fringe benefits, achievements, autonomy, and recognition, communication, working condition, job importance, positive affectivity, job security workplace flexibility and other factors. The primary objective of this study is to examine the nature and magnitude of relationship between leadership styles and job satisfaction prevailing in the various business sectors in Nepal.
\end{abstract}

Key words: Management, Job satisfaction, leadership, job security, communication

*Dr. Mathema is a Professor, Faculty of Management, Nepal Commerce Campus, Tribhuvan University. Corresponding email:sushil.mathema@yahoo.com. 


\section{Introduction}

Comprehensive definition of job satisfaction is involving cognitive, affective and evaluative reactions or attitudes. It is a pleasurable or positive emotional state resulting from the appraisal of ones job or job experience. Different organizational employees may have different attitudes towards their jobs. They may have different attitudes about pay, nature of jobs, management behaviour, working environment, and performance evaluation system of the company. Some employees may have positive attitudes and some employees may have negative attitudes. Thus job satisfaction is the extent to which a person is gratified or fulfilled by his or her work. The term job satisfaction describes how content an individual is with their job. It is a relatively recent term since in previous centuries the jobs, available to a particular person were often predetermined by their parents' occupation. Therefore as mentioned above there are varieties of factors that can influence a person's level of satisfaction.

\section{Job Related Satisfaction}

The conceptualization of the concept of job satisfaction in this study has been derived from the definition offered by Locke (1976). He defined job satisfaction as a favorable attitude or pleasurable emotional state that results from a person's experience or a fit between a person and organization "job satisfaction is influenced by a number of factors which are closely related to the job, management practices, pay and other incentives".

Job Satisfaction is often considered as a composite of several satisfactions. Job related satisfaction is one of the significant constituents of overall job satisfaction. This dimension of job satisfaction consists of the level of satisfaction the employees perceive in all factors which are closely related to job such as clarity fitness between knowledge and job, value of job perceived by the organization, adequacy of time and resources in performing the job, interdependency opportunity for innovative career orientation, sense of satisfaction and consideration of efficiency and skill before assigning the job.

In order to examine the level of job related satisfaction as perceived by the employees, the selected respondents have been provided as many as eleven statements to be rated on a scale of 1(strongly disagree) to 5 (strongly agree). The statements included in the questionnaire in order to examine the level of job related satisfaction are statement numbers 1, 2, 3, 4, 5, 6, 7, 8, 9, 10 and 19.

Thus an individual respondent's maximum score would be 55 and the minimum score would be 11. Higher the score, the more is the level of satisfaction. Job related satisfaction has been analyzed sector wise, sex wise, experience group wise and age group wise. The mean score of these respondent groups, their standard deviations and co-efficient of variation have been used to analyze the response. 


\section{Table 1}

\section{Job-related Satisfaction by Sectors}

\begin{tabular}{|c|c|c|c|c|c|c|c|c|c|c|}
\hline \multirow{2}{*}{ Sector } & \multicolumn{9}{|c|}{ Job related satisfaction } & \multicolumn{4}{c|}{ Percentage } \\
\cline { 2 - 13 } & $\mathrm{N}$ & Mean & $\mathrm{SD}$ & $\mathrm{CV}$ & \multicolumn{2}{|c|}{ Weighted Score } & Low & Medium & High & $\mathrm{N}$ \\
\hline $\begin{array}{c}\text { Finance (Bank \& } \\
\text { Insurance) }\end{array}$ & 350 & 3.73 & 0.615 & 16.48 & 0.7465 & 74.65 & 6 & 132 & 212 & 74 \\
\hline Manufacturer & 75 & 3.71 & 0.686 & 18.50 & 0.74186 & 74.186 & 0 & 33 & 41 & 43 \\
\hline Hotel & 43 & 3.97 & 0.739 & 18.61 & 0.79414 & 79.414 & 2 & 12 & 29 & 38 \\
\hline Trading & 38 & 4.12 & 0.672 & 16.31 & 0.8241 & 82.41 & 1 & 6 & 31 & 505 \\
\hline Total & 506 & 3.779 & 0.651 & 17.22 & 0.7557 & 75.57 & 9 & 183 & 313 & \\
\hline
\end{tabular}

Table 1 presents the sector wise job related satisfaction. Job related satisfaction is highest in trading sector; the mean score of responses is 4.12 the weighted score of which is $82.41 \%$ which is very much close to the maximum satisfaction scale of 5. Job related satisfaction in manufacturing sector is the lowest among the four sectors selected for the purpose of the study in which the mean satisfaction score is 3.71 the weighted score of which is $74.19 \%$. On an average the level of job related satisfaction as perceived by the respondents is above the average level of 3.

The respondents of the various sectors seem to have varying perception with regard to the level of job related satisfaction in various elements (Table 1). Element "value of job" has been perceived as having the highest level of satisfaction by all the sectors. Although no element of job related satisfaction has been found with the mean of less than the mid value.

Table 2

\section{Interco relation Among Sectors With Respect to job-related Satisfaction}

\begin{tabular}{|c|c|c|c|}
\hline Sector & \multicolumn{3}{|c|}{ Job related satisfaction } \\
\hline Finance & - & - & \\
\hline Manufacturer & $0.43^{*}$ & $0.56^{*}$ & - \\
\hline Hotel & $0.48^{*}$ & $0.41^{*}$ & $0.58^{*}$ \\
\hline Trading & $0.68^{*}$ & *Significant at 0.01 level \\
\hline
\end{tabular}

Table 2 presents the analysis of level of job related satisfaction as perceived by both sex. Both male and female respondents seem to hold same perception towards the level of job related satisfaction the mean scores of whose are 3.77 and 3.79 respectively. 
Table 3

\section{Job-related Satisfaction by Sex}

\begin{tabular}{|c|c|c|c|c|c|c|c|c|c|c|}
\hline \multirow{2}{*}{ Sex } & \multicolumn{4}{|c|}{ Job related satisfaction Mean } & \multicolumn{4}{c|}{ Response distribution } \\
\cline { 2 - 12 } & N & Mean & SD & CV & \multicolumn{2}{|c|}{ Weighted Score } & Low & Medium & High & N \\
\hline Male & 391 & 3.774 & 0.647 & 17.15 & 0.7547 & 75.47 & 6 & 144 & 240 & 390 \\
\hline Female & 115 & 3.795 & 0.665 & 17.52 & 0.75904 & 75.904 & 3 & 39 & 73 & 115 \\
\hline Total & 506 & 3.779 & 0.651 & 17.22 & 0.7557 & 75.57 & 9 & 183 & 313 & 505 \\
\hline
\end{tabular}

An examination of element wise analysis suggests that both male and female respondents perceive element "value of job" the most satisfied element the mean scores of which for male and female respondents are 4.37 and 4.42 respectively. No element of job related satisfaction has been noted less than the average of 3 .

\section{Table 4}

\section{Element-wise Analysis of job-related Satisfaction by Sex}

\begin{tabular}{|l|c|c|c|c|c|c|c|c|c|c|}
\hline & \multicolumn{3}{|c|}{ Male } & \multicolumn{3}{c|}{ Female } & \multicolumn{3}{c|}{ Total } & \\
& & Mean & N & SD & Mean & N & SD & Mean & N & SD \\
\\
\hline JQ_1_J & 4.03 & 390 & 1.089 & 3.97 & 115 & 1.135 & 4.02 & 505 & 1.099 & 0.24 \\
\hline JQ_2_J & 3.82 & 390 & 1.091 & 3.77 & 115 & 1.165 & 3.81 & 505 & 1.107 & 0.24 \\
\hline JQ_3_J & 4.37 & 390 & 0.886 & 4.42 & 115 & 0.772 & 4.38 & 505 & 0.861 & 0.24 \\
\hline JQ_4_J & 3.41 & 388 & 1.181 & 3.86 & 113 & 1.101 & 3.51 & 501 & 1.177 & $13.00 *$ \\
\hline JQ_5_J & 3.7 & 390 & 1.068 & 3.71 & 115 & 1.024 & 3.7 & 505 & 1.057 & 0.01 \\
\hline JQ_6_J & 4.01 & 388 & 0.925 & 4.05 & 114 & 0.976 & 4.02 & 502 & 0.939 & 0.20 \\
\hline JQ_7_J & 3.51 & 387 & 1.107 & 3.44 & 113 & 1.085 & 3.5 & 500 & 1.101 & 0.34 \\
\hline JQ_8_J & 3.52 & 388 & 1.138 & 3.6 & 114 & 1.111 & 3.54 & 502 & 1.131 & 0.40 \\
\hline JQ_9_J & 4.15 & 388 & 0.922 & 3.97 & 113 & 1.089 & 4.11 & 501 & 0.964 & 3.10 \\
\hline JQ_10_J & 3.6 & 388 & 1.07 & 3.38 & 114 & 1.124 & 3.55 & 502 & 1.086 & 3.58 \\
\hline JQ_19_J & 3.65 & 386 & 1.221 & 3.87 & 115 & 1.056 & 3.7 & 501 & 1.188 & 3.03 \\
\hline
\end{tabular}

The correlations or responses of both groups are positive and significant $(\mathrm{r}=0.421)$ 
Table 5

\section{Correlations between Sex with Respect job-related Satisfaction}

\begin{tabular}{|c|c|c|c|}
\hline \multicolumn{2}{|c|}{} & Job related Male & $\begin{array}{c}\text { Job related } \\
\text { Female }\end{array}$ \\
\hline Job related Male & Pearson Correlation & 1 & $0.421^{*}$ \\
& Sig. * 2-talled) & - & 0.000 \\
& N & 391 & 115 \\
\hline Job related Female & Pearson Correlation & $0.421 * *$ & 1 \\
& Sig. * 2-talled) & 000 & - \\
& N & 115 & 115 \\
\hline
\end{tabular}

**Significant at 0.05 level

*Significant at 0.01 level

Experience wise analysis of job related satisfaction has been presented in Table 5 .

Table 6

\section{Job related Satisfaction by Experience Groups}

\begin{tabular}{|c|c|c|c|c|c|c|c|c|c|}
\hline Service/ & \multicolumn{6}{|c|}{ Job related satisfaction Mean } & \multicolumn{3}{|c|}{ Response Distribution } \\
\hline & $\mathrm{N}$ & Mean & SD & $\mathrm{CV}$ & Weighted Score & SD & Low & Medium & High \\
\hline Up to 5 & 123 & 3.787 & 0.685 & 18.08 & 0.75734 & 75.734 & 3 & 40 & 80 \\
\hline 6 to 10 & 188 & 3.895 & 0.648 & 17.08 & 0.759 & 75.9 & 9 & 77 & 102 \\
\hline 11 to 15 & 82 & 4.023 & 0.503 & 12.50 & 0.80458 & 80.458 & 3 & 26 & 53 \\
\hline 16 to 20 & 73 & 3.532 & 0.696 & 19.71 & 0.70632 & 70.632 & 2 & 38 & 33 \\
\hline More than & 40 & 3.779 & 0.594 & 15.64 & 0.75978 & 75.978 & 1 & 10 & 29 \\
\hline Total & 506 & 3.779 & 0.651 & 17.23 & 0.5572 & 75.572 & 18 & 191 & 297 \\
\hline
\end{tabular}

The mean scores of the responses of all experience groups are greater than the mid value of 3 the aggregate mean of which is 3.78 . However the highest level of job related satisfaction has been perceived by the experience group of 11 to 15 years whose mean score is 4.02 . Experience group of 16 to 20 years has perceived the lowest level of satisfaction with the mean score of 3.53. From the element wise analysis, it has been observed that element "value of job" has been perceived the most satisfaction element by all experience groups the aggregate mean of responses of which is 4.38. No experience group has been found to perceive any element satisfaction less than the average. Responses of different experience groups have been found to vary significantly with respect to the elements such as "Adequacy of resources", "Sense of satisfaction" and "consideration of efficiency and skill".

\section{Summary and Conclusions}

All four sectors taken in this study have been found to adopt average level of prevalence of democratic style. In trading sector, democratic leadership style prevails to the highest extent and the lowest in manufacturing sector. Democratic style prevails to average extent for the managers of both genders, of all age groups, and of all experience groups. The pattern of democratic leadership style prevailing in hotel, finance, and trading sectors is much alike as evidenced by the inter correlation analysis. The views of the managers of genders, all age groups, and all experienced groups are also almost similar regarding the extent of prevalence of the various elements of the democratic leadership style. 
Autocratic leadership style prevails at moderate extent in for sectors and for gender, all age groups, and all experience group managers. The highest autocratic style prevails in hotel sector. Both male and female managers perceive almost equal magnitude of autocratic style. The level of management related dimension of job satisfaction is above the average in all sectors and for all genders, age groups, and experience groups. The highest level of management related satisfaction prevails in trading sector. Female managers perceive little more satisfaction than the male managers. Highest level of participation as well as the highest level of overall satisfaction prevails in trading sector. Female managers perceive slightly more participation and overall satisfaction than the male managers.

\section{REFERENCES}

Arvey. R. D.et al., (1989). Job satisfaction: Environmental and genetic components. Journal of Applied Psychology, 74.

Arya, P.P. (1984). Work satisfaction and its correlates. Indian Journal of Industrial Relations.

Austin, D.L. (1976). Conflict: A More Professional Approach. Personnel Administrator, 21, July.

Balaji, C. (1988). Organizational Commitment of Job Satisfaction Which Explains Intent to Quite Better. Indian Journal of Industrial Relations, Vol. 24.

Bales, R.F. (1950). A set of categories for the analysis of small group interaction, American Sociological Review, 15.

Bali, R.R. (1967). "Worker's Attitude to Work: A Study of Refugee Workers". Indian Journal of Industrial Relations, Vol. 3(2).

Bass, B.M. (1985). Leadership and performance beyond expectations. New York: Free Press.

Bass, B.M. \& Avolio B.J. (1960). Leadership, psychology and Organizational Behaviour. New York. Harper 1960 (1989). Potential biases in leadership.

Locke, E.A. and associates (1991) The essence of Leadership: the Four Keys to Leading Successfully. New York: Lexington. 